\title{
Effects of Prenatal Drug Exposure on Children's Working Memory: A Systematic Review
}

\author{
Samariz Laboy-Hernández, PhD', Nelson D. Cruz-Bermúdez, PhD'1, Guillermo Bernal, PhD² \\ 'Department of Psychology, University of Puerto Rico, Río Piedras Campus, San Juan, Puerto Rico \\ ${ }^{2}$ Department of Psychology and Institute for Psychological Research, University of Puerto Rico, Río Piedras Campus, San Juan, Puerto Rico
}

Received: May 8, 2020

Revised: June 22, 2020

Accepted: June 24, 2020

\section{Corresponding author:}

Nelson D. Cruz-Bermúdez, PhD

Department of Psychology,

University of Puerto Rico, Río

Piedras Campus, 9 Ave Universidad,

Suite 901, San Juan 00925, Puerto

Rico

Tel: +1-787-764-0000 (87570)

Fax: +1-787-763-4599

E-mail:nelson.cruz6@upr.edu
Purpose: Substance use during pregnancy is a public health problem. Prenatal drug exposure (PDE) is linked to abnormal physical growth, altered brain organization, and cognitive, emotional, and behavioral problems later in life. Working memory (WM) plays an important role in the cognitive processes required for academic achievement, particularly for problem-solving, planning, and decision-making. The purpose of this study was to conduct a systematic review of studies measuring the effect of PDE on children's WM.

Methods: Using the Joanna Briggs Institute Reviewers' Manual, we systematically reviewed eight studies (published 2008 to 2019) that measured the effects of PDE on WM among children ages 5 to 12 .

Results: Studies measuring prenatal exposure to methamphetamine, tobacco, or cocaine did not find differences in WM between PDE groups and controls. Nonetheless, three of the studies found that alcohol had negative effects on children's WM, pinpointing the potential of alcohol to disrupt neurocognitive development.

Conclusion: We were not able to generate conclusions regarding the consequences of PDE on children's WM, but we discuss methodological issues and implications for future research on this phenomenon.

Keywords: Child; Prenatal exposure delayed effects; Systematic review; Memory, short-term

\section{Introduction}

Despite adverse effects on children, poly-substance use during pregnancy continues to be a major public health issue [1]. Psychoactive drugs are toxic to the developing brain, especially during the second and third trimester of pregnancy [2]. Given that insults to the central nervous system have their greatest impact upon cells, circuits and processes that are in accelerated development during the fetal period [3], maternal substance use is strongly associated with short- and long-term negative neurological consequences on the offspring. Short-term effects include abnormal brain growth and organization [4], along with long-term effects that comprise serious cognitive, emotional, behavioral and social problems [5]. Prenatal drug exposure (PDE) is considered a risk factor affecting children's development and thus, it has received considerable attention by researchers in recent years [6-9].

According to averaged data (2012 to 2013) from the National Survey on Drug Use and Health of the United States (NSDUH), about $15.4 \%$ of pregnant women ages 15 to 44 had smoked cigarettes, 9.4\% used alcohol, and 5.4\% used illicit drugs [10]. Like-

Copyright (C) 2020 Korean Child Neurology Society

This is an Open Access article distributed under the terms of the Creative Commons Attribution Non-Commercial License (http://creativecommons.org/licenses/by-nc/4.0/) which permits unrestricted non-commercial use, distribution, and reproduction in any medium, provided the original work is properly cited. 
wise, between $7 \%$ and $11 \%$ of European women with substance use problems become pregnant or give birth every year [11]. Although prevalence rates have reached levels of concern, most data are usually obtained with self-reports and thus, substance use in pregnant women might be underestimated due to the stigma and potential legal consequences [3,12-14]. This in turn suggests that more children than those officially reported might have been exposed to drugs in utero.

\section{PDE and working memory}

PDE effects on cognitive processes have been previously studied [15-19]. For instance, researchers have found a relationship between prenatal tobacco exposure (PTE) and reduced cognitive abilities and academic achievement later in the life [16]. Results from other studies suggest that binge drinking during pregnancy have detrimental effects on children's cognition [18]. However, fewer studies have specifically examined how PDE affects children's working memory (WM). WM is broadly defined as the mechanism for retaining a small amount of information in the mind in a temporary state of availability [20]. There are different assessments to measure WM in children for research, clinical and educational purposes including the Digit Span subtest of the Wechsler Intelligence Scale for Children (WISC) [21] and the N-back task [22]. In the Discussion section, we consider issues related to WM measures.

WM has become a major research topic because of its key role on skills and processes required for academic success, which is the main task of children ages 5 through the teenage years [23]. Multiple studies have highlighted the predictive role of WM on academic achievement as well as its relationship with mathematic performance, language comprehension, reading, writing, and problem solving at different developmental stages [24-32]. Taken together, it is reasonable to argue that WM deficits often underlie academic underachievement. However, WM deficits are modifiable and can be identified early, even before academic difficulties become obvious [33]. Ignoring WM deficits might result in deleterious longterm consequences in the child's health, behavior, and well-being.

\section{WM and development}

Neuroimaging studies have revealed pronounced growth and changes taking place between the ages of 5 and 12 years [34] and much of the WM development occurs after the age of 5 [35]. Cognitive, physical, motor and emotional developmental changes occurring during this period also influence performance on WM assessments. Children usually begin school when they are 5 years old, making it an excellent stage to evaluate WM. With respect to PDE, effects become evident after children begin school when marked increases in cognitive competences are demanded. Therefore, considering the relationship between PDE, WM and children development, we asked the following question in the present study: what are the effects of prenatal exposure to drugs on the WM of children ages 5 to 12 ? We carried out a systematic review of scientific publications to expand upon existing literature and have a better understanding of the latest research on PDE. Early identification of legal and illicit drugs' effects on children cognition makes possible to take advantage of the developing brain plasticity to implement interventions aimed at maximizing improvement and preventing future learning problems [36-38].

\section{Materials and Methods}

\section{Study protocol}

We used the Joanna Briggs Institute Reviewers' Manual (JBI-RM) to develop the protocol for this systematic review before conducting the study [39]. The Joanna Briggs Institute is an independent, international organization focused on researching evidence-based healthcare and improving global health. The manual provides detailed guidelines for systematic reviews and meta-analyses. The protocol included the selection of the study designs, population, interventions, comparison groups, measures, search strategy, inclusion/exclusion criteria and critical appraisal (risk of bias assessment). This review includes peer-reviewed journal articles published between 2008 and 2019, in English or Spanish, measuring WM in both male and female children ages 5 to 12 years with a history of prenatal exposure to legal and/or illegal drugs. We narrowed the years of publication (2008 to 2019) to have a precise understanding of the latest research published on this topic.

\section{Search strategy}

Fig. 1 summarizes our search strategy. We first carried out a limited search in PubMed and PsycINFO, which are two of the largest databases devoted to peer-reviewed research in biomedicine and behavioral sciences using the following four keywords: prenatal, drugs, exposure, and WM. We analyzed words contained in the titles, abstracts and keywords of the retrieved publications and validated the English and Spanish synonyms of the words for accurate correspondence. Posteriorly, we performed a more inclusive search using an extended set of keywords and their relevant combinations in both English and Spanish: prenatal, fetal, drugs, substances (and specific types such as cocaine, heroin, etc.), exposure, effect, WM, measurement, performance, assessment, and outcome. We searched the following databases: Ebsco Host Research Databases (Academic Search Complete, Fuente Académica, Psychology and Behavioral Sciences Collection, PsycINFO, Medline), Proquest 


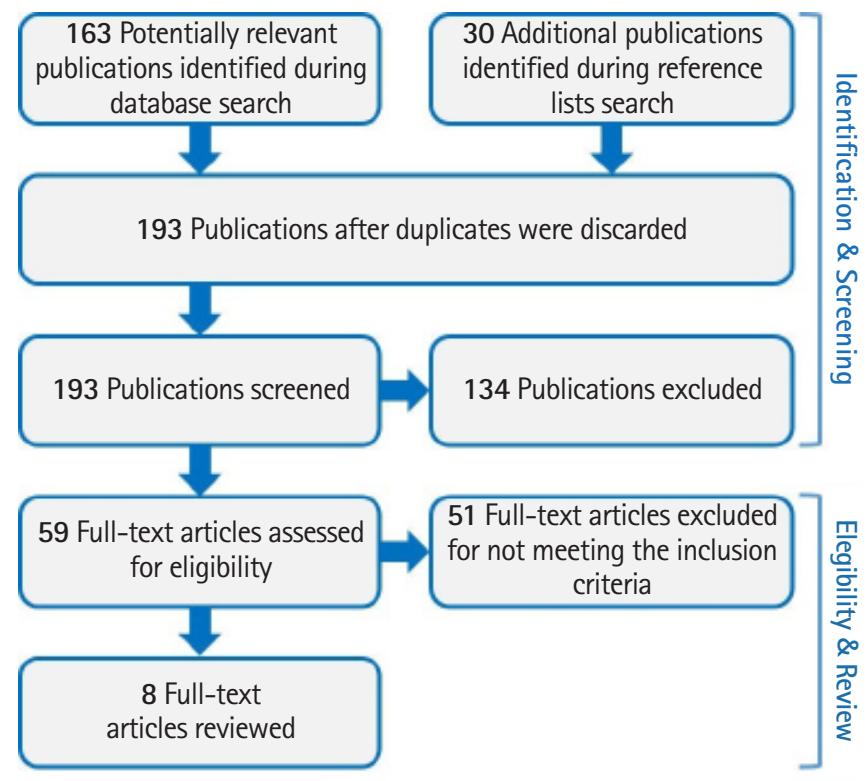

Fig. 1. Flowchart of the search strategy and article selection.

(Psychology Journals, Science Journals), PubMed, Cambridge University Press, Gale-Cengage (Academic Journals), Oxford Journals, Sage, Science Direct, Springer Link-Journals, Taylor and Francis, and Mendeley. To narrow our search, we used the advanced search options by date range, age and other filters as allowed by each database. We also searched for additional studies in the reference list of all identified papers.

The titles and abstracts of the retrieved articles were carefully reviewed and those that did not clearly meet general criteria were discarded (e.g., animal studies, no outcome of interest). At this point, we applied the detailed inclusion criteria assessment to the articles that had higher possibilities to be included in this review. Studies must have included the following elements: (1) an unexposed group of children as a control; (2) measures of drug use during pregnancy; and (3) control of confounding variables. We contacted the corresponding authors of two publications to request additional information about the measures they used and results obtained in their respective studies. During the analysis, we also reviewed the literature to have detailed descriptions of the WM measures used in those studies. Such information allowed doing a documented decision regarding whether or not the tests or tasks used in those studies were indeed measures of WM.

\section{Critical appraisal and data extraction}

Our main outcome of interest was studies measuring WM in children who were exposed to psychoactive drugs in utero. Articles that met the inclusion criteria according to the protocol (see Results), were subjected to a rigorous risk of bias assessment complet- ed the first two authors (critical appraisers). We used the JBI Critical Appraisal Tools approved by the JBI Scientific Committee for systematic reviews, available online (http://joannabriggs.org/research/critical-appraisal-tools.html). We particularly used the checklists for cohort studies and analytical cross sectional studies. Using the JBI-RM, we then extracted relevant information from each article, including the study sample, characteristics and raw data (e.g., weighted mean differences, standard deviations [SDs]) and performed a narrative synthesis by type of drug with the extracted information [39].

\section{Results}

We identified 193 publications during the initial search. From that pool, 59 articles were considered as either relevant or of uncertain relevance based on words within the titles and abstracts, and were obtained for full text reading. Out of the 59 studies, we found eight $(n=8)$ that met our inclusion criteria (Fig. 1): two studies of methamphetamine, three of alcohol, one of tobacco and two of cocaine. After carrying out a critical appraisal on each study to identify possible biases, we found that the eight studies complied with the methodological quality (as quantified separately by each appraiser) and were included in the review. In the next sections, we briefly describe general aspects of each study and report the mean and SD of WM measurements. Table 1 includes other relevant details.

\section{Prenatal methamphetamine exposure}

Abar et al. [40] analyzed data from the Infant Development, Environment and Lifestyle (IDEAL) longitudinal study on prenatal methamphetamine exposure (PME). Children were engaged in a series of tasks testing executive function and examiners were blind to methamphetamine exposure status. As part of the battery of tests, the authors used the Attention/Concentration index from the Children's memory scale (CMS), which provides measures of attention and WM [41]. The index mean was 96.33 (SD 14.99) for the PME group and 97.71 (SD 17.56) for the control group, but there were no statistically significant differences in WM (nor executive function) between groups.

Piper et al. [42] carried out a cross-sectional study with children from similar socioeconomic status who were exposed or not to methamphetamine or poly-substances during pregnancy. Children performed a battery of neurobehavioral tests including the Spatial Span subtest of the Wechsler Intelligence Scale for Children IV Integrated (WISC-IV), which offers a measure of visual-spatial WM. In the subtest forward condition, the mean raw score was 5.3 (SD 0.3 ) for the PME group and 5.7 (SD 0.3) for the unexposed group. In the backward condition, the mean was 4.5 (SD 0.4) for PME 
Table 1. Summary of the eight studies reviewed

\begin{tabular}{|c|c|c|c|c|}
\hline Study & Design/Sample & Measures & Confounder controls & PDE effect on WM \\
\hline $\begin{array}{l}\text { Abar et al. (2013) } \\
\text { [40] }\end{array}$ & $\begin{array}{l}\text { Longitudinal; } n=320 \text { (PME } \\
\text { group, 162; control group, } \\
\text { 158); 6.5-year follow-up of } \\
\text { children from } 4 \text { United States } \\
\text { cities (Los Angeles, Des } \\
\text { Moines, Tulsa, and Honolulu). }\end{array}$ & $\begin{array}{l}\text { PDE: Maternal self-report or } \\
\text { infant meconium immunoassay } \\
\text { and gas chromatography } \\
\text {-mass spectrometry. } \\
\text { WM: Attention/ concentration } \\
\text { index from the CMS }\end{array}$ & $\begin{array}{l}\text { Neonatal characteristics, } \\
\text { maternal age at birth, } \\
\text { maternal quantity of } \\
\text { self-reported drug use while } \\
\text { pregnant and city. Early } \\
\text { adversity was included as a } \\
\text { mediator of the effect of PME. }\end{array}$ & $\begin{array}{l}\text { No significant differences by } \\
\text { exposure condition. }\end{array}$ \\
\hline $\begin{array}{l}\text { Piper et al. (2011) } \\
\text { [42] }\end{array}$ & $\begin{array}{l}\text { Cross-sectional; } n=66 \\
\text { (methamphetamine/ } \\
\text { polysubstance exposed group, } \\
\text { 31; unexposed group, 35); } \\
\text { 7-9-year-old children from } \\
\text { Oregon, USA. }\end{array}$ & $\begin{array}{l}\text { PDE: Medical records, maternal } \\
\text { questionnaire and urine } \\
\text { analysis or maternal legal } \\
\text { documentation provided by } \\
\text { adoptive parents. } \\
\text { WM: Spatial Span test from the } \\
\text { WISC-IV-Integrated }\end{array}$ & $\begin{array}{l}\text { ADHD diagnosis and PDE. } \\
\text { Unexposed children were } \\
\text { recruited from the same } \\
\text { community based on similar } \\
\text { household income during } \\
\text { pregnancy and age as exposed } \\
\text { children. }\end{array}$ & $\begin{array}{l}\text { No significant differences by } \\
\text { exposure condition. }\end{array}$ \\
\hline $\begin{array}{l}\text { Aragon et al. } \\
\text { (2008) [43] }\end{array}$ & $\begin{array}{l}\text { Longitudinal; } n=80 \text { (FASD } \\
\text { group, 23; control group, 57); } \\
\text { 6-7-year-old Italian children. }\end{array}$ & $\begin{array}{l}\text { PDE: Maternal questionnaire. } \\
\text { WM: Memory subtest from the } \\
\text { WISC-R (Italian translation). }\end{array}$ & $\begin{array}{l}\text { Matched controls were } \\
\text { randomly selected from the } \\
\text { same first-grade cohort in the } \\
\text { same schools. Maternal age, } \\
\text { education attainment, and } \\
\text { monthly income were similar. }\end{array}$ & $\begin{array}{l}\text { Significant differences by } \\
\text { exposure condition. Children } \\
\text { diagnosed with FAS or PFAS } \\
\text { had lower scores on WM. }\end{array}$ \\
\hline $\begin{array}{l}\text { Diwadkar et al. } \\
\text { (2013) [44] }\end{array}$ & $\begin{array}{l}\text { Longitudinal; } n=47 \text { (FAS/PFAS } \\
\text { group, } 17 ; \text { heavily exposed } \\
\text { non-syndromal group, 13; } \\
\text { control group, 17); } \\
\text { 8.9-10.6-year-old colored } \\
\text { children from Cape Town, } \\
\text { South Africa. }\end{array}$ & $\begin{array}{l}\text { PDE: Maternal interview } \\
\text { WM: Verbal N-back task (letters } \\
\text { as stimulus) }\end{array}$ & $\begin{array}{l}\text { Maternal SES, years of } \\
\text { education, marital status, age } \\
\text { at delivery, parity, and smoking } \\
\text { during pregnancy, and child } \\
\text { gender, total intracranial } \\
\text { volume, age at assessment, } \\
\text { IQ, and postnatal lead exposure. }\end{array}$ & $\begin{array}{l}\text { Both groups of exposed children } \\
\text { performed poorly than } \\
\text { controls on the 2-back task, } \\
\text { but the three groups } \\
\text { performed well on the 1-back } \\
\text { paradigm. }\end{array}$ \\
\hline $\begin{array}{l}\text { Quattlebaum et al. } \\
\text { (2013) [47] }\end{array}$ & $\begin{array}{l}\text { Cross-sectional; } n=125 \text { (PAE } \\
\text { group, 97; non-exposed } \\
\text { group, 28); 6-12-year-old } \\
\text { children from California, USA. }\end{array}$ & $\begin{array}{l}\text { PDE: Biological mother } \\
\text { interview. Among adopted or } \\
\text { foster children, medical or } \\
\text { legal documentation and } \\
\text { witness reports were obtained. } \\
\text { WM: Digit Span and Spatial } \\
\text { Span subtests of the WISC-III PI }\end{array}$ & $\begin{array}{l}\text { IO was the sole controlled } \\
\text { variable. }\end{array}$ & $\begin{array}{l}\text { WM was significantly different } \\
\text { for the PDE group, but only } \\
\text { the Spatial Span group } \\
\text { differences remained } \\
\text { significant after controlling } \\
\text { for IO. }\end{array}$ \\
\hline $\begin{array}{l}\text { Singer et al. (2008) } \\
\text { [50] }\end{array}$ & $\begin{array}{l}\text { Longitudinal; } n=371 \text { (PCE group, } \\
\text { 192; control group, 179); } \\
\text { primarily 9-year-old African } \\
\text { American children. }\end{array}$ & $\begin{array}{l}\text { PDE: Maternal report, urine } \\
\text { samples and meconium } \\
\text { analysis. } \\
\text { WM: WM subtests of the } \\
\text { WISC-IV }\end{array}$ & $\begin{array}{l}\text { Covariates accounting for } \\
\text { demographic, environmental, } \\
\text { and medical factors. }\end{array}$ & $\begin{array}{l}\text { No significant differences by } \\
\text { exposure condition. }\end{array}$ \\
\hline
\end{tabular}

PDE, prenatal drug exposure; WM, working memory; PME, prenatal methamphetamine exposure; CMS, Children's Memory Scale; WISC, Wechsler Intelligence Scale for Children; ADHD, attention deficit hyperactivity disorder; FASD, fetal alcohol spectrum disorders; PFAS, partial fetal alcohol syndrome; FAS, fetal alcohol syndrome; SES, socioeconomic status; IQ, intelligence quotient; PAE, prenatal alcohol exposure; PTE, prenatal tobacco exposure; PCE, prenatal cocaine exposure.

group and 4.9 (SD 0.4) for the unexposed group. There were no statistically significant differences in visual-spatial WM in either condition between groups.

\section{Prenatal alcohol exposure}

Aragon et al. [43] compared the neuropsychological functioning of children with fetal alcohol spectrum disorders (FASDs) and normal children in the context of a larger epidemiological project. Examiners were blind as to the conditions. Participants completed psychological and developmental evaluations using a battery of tests, including the Italian version of the WISC-R. That scale contains 12 subtests that make up a verbal intelligence quotient (IQ), 
performance IQ, and full-scale IQ. The memory subtest measures WM and is part of the verbal IQ. In that subtest, the mean was 8.13 (SD 3.42) for the FASD group and 10.23 (SD 3.10) for the control group, but there were no statistically significant differences between groups. When comparing the two groups on the verbal, performance, and full scale mean IQ scores from the WISC-R, the FASD group showed significantly lower scores on verbal IQ, performance IQ, and full-scale IQ.

Diwadkar et al. [44] used the n-back task and functional magnetic resonance imaging (fMRI) to measure and compare WM in three groups: children with full fetal alcohol syndrome (FAS) or partial fetal alcohol syndrome (PFAS); children heavily exposed to alcohol (HE) without FAS or PFAS; and control children. The examiners were blind with regard to maternal alcohol consumption history and children diagnose. The principal n-back task outcome was d-prime, which measures the "number of correct button presses, adjusted for false alarms, to correct for any tendency to press the same button regardless of whether the stimulus was seen previously" [44]. They measured WM inside and outside of the MRI scanner.

For the 1-back task outside the scanner, the d-prime mean was 2.41 (SD 0.78) for the FAS/PFAS group, 2.12 (SD 0.75) for the HE group and 2.25 (SD 1.01) for the control group. For the 1-back task inside the scanner, the d-prime mean was 2.14 (SD 0.81) for the FAS/PFAS group, 2.12 (SD 0.80) for the HE group and 2.26 (SD 0.81) for the control group. There were no statistically significant differences in the 1-back task between groups either outside or inside the MRI scanner. For the 2-back task outside the scanner, the d-prime mean was 1.13 (SD 0.67) for the FAS/PFAS group, 0.99 (SD 0.47) for the HE group and 1.39 (SD 0.72) for the control group. Again, there were no statistically significant differences in the 2-back task between groups. fMRI data indicated that the three groups recruited different elements of the cortico-striatal-cerebellar network, which is known to be involved in WM [45,46]. In terms of IQ assessment, all the children were administered the Weschler Intelligence Scale for Children, fourth edition (WISCIV). The WISC-IV measures intellectual ability of children from 6 to 16 years and provides an overall measure of general cognitive ability. It also measures intellectual functioning in verbal comprehension, perceptual reasoning, WM, and processing speed. The IQ scores of the children in the FAS/PFAS group were lower than the controls and tended to be lower than those in the HE group.

Quattlebaum and O'Connor [47] carried out a comprehensive, multi-informant assessment of neurocognitive, emotional, social, behavioral, and adaptive functioning in children with FASD, which included the Wechsler Intelligence Scale for Children-III as a Process Instruments (WISC-III PI). The WISC-III PI contains 19 subtests and complements the WISC-III by allowing to identify which process is deficient when the examinees perform poorly in the latter. They measured WM using the Digit Span and Spatial Span subtests of the WISC-III PI. In the Digit Span task, means were 8.68 (SD 3.07) for the prenatal alcohol exposure (PAE) group and 10.14 (SD 2.72) for the control group, and in the Spatial Span task, means were 8.35 (SD 3.57) for the PAE group and 11.61 (SD 3.14) for the control group. Both subtests produced a statistically significant overall effect after controlling for IQ, although the individual effect of the Digit Span subtest was not statistically significant. The IQ was assessed with the Kaufman Brief Intelligence Test, a brief individually administered measure of verbal and non-verbal intelligence.

\section{Prenatal tobacco exposure}

Bennett et al. [48] used an event-related fMRI design to measure brain activity and WM using the n-back task in a sub-sample of a longitudinal PDE study. The mean of omission errors in the n-back task was 11.4 (SD 7.1) for PTE group and 8.1 (SD 4.9) for controls, and the mean of commission errors was 2.7 (SD 2.0) for PTE and 4.9 (SD 5.0) for controls. However, there were no statistically significant differences in the n-back task performance between groups. In terms of neuroimaging, the authors found statistically significant differences in whole brain activation between PTE children and controls during correct responses. The PTE group showed greater activation of inferior parietal regions, whereas control children showed greater activation of bilateral inferior frontal regions during the WM task.

\section{Prenatal cocaine exposure}

The neurocognitive study of Hurt et al. [49] was designed to assess the effects of prenatal cocaine exposure (PCE) on different domains. They measured WM using the spatial WM task and the Letter Two-Back task. In the spatial WM task, the mean error score was $48.8 \pm 15.4$ for PCE and $46.7 \pm 17.3$ for controls and the standard score was $93.4 \pm 9.2$ for PCE and $93.4 \pm 11.3$ for controls. In the Letter Two-Back task, the mean total correct score was $108.5 \pm 5.8$ for PCE and 108.1 \pm 6.1 for controls. Authors stated that the WM scores were in the average range, with all scores falling below the mean for the standardization sample. They found no statistically significant differences between groups and no evidence of WM impairment caused by PCE after controlling for multiple confounding child and environmental variables.

Singer et al. [50] conducted a cognitive and school achievement assessment as part of a longitudinal study. The study examiners were unaware of the children's cocaine exposure status. They measured WM using the WISC-IV. The mean WM IQ was 88.56 (SD 
14.20) for the PCE group and 89.84 (SD 16.28) for the unexposed group. They found no statistically significant differences between groups, although discrete effects of alcohol exposure were discernible on WM IQ.

\section{Discussion}

The aim of this study was to review the effect of PDE on children's WM in light of published literature regarding the negative consequences of poly-substance use during pregnancy. Specifically, this systematic review included eight studies measuring WM in children prenatally exposed to methamphetamine, alcohol, tobacco, or cocaine. We discuss relevant findings, inconsistencies between studies and limitations of this systematic review.

\section{Methamphetamine and WM}

Although no significant effects of PME in children's WM were found in the two studies reviewed $[40,42]$, results were possibly affected by distinct limitations. For example, Piper et al. [42] used a small sample and did not control for the effect of attention deficit hyperactivity disorder pharmacotherapy, which is known to enhance cognitive performance $[51,52]$. Nonetheless, both studies reported important findings about executive functions. Abar et al. [40] pointed that although they did not observe direct effects of PME on executive function deficits, there was an indirect effect through early adversity. According to Piper et al. [42], the neurobehavioral assessments revealed pronounced executive dysfunction and a slight reduction in spatial memory. Based on those observations, interventions for neurobehavioral remediation in children prenatally exposed to drugs were suggested. Currently, PME studies in general [8], and their possible effects on children's WM in particular are scarce and thus, the available information is not enough to establish clear conclusions about the interaction between PME and WM in children.

\section{Alcohol and WM}

All three studies reviewed here found negative effects of PAE on children's WM. Results were expected because it had been established that PAE produces a variety of effects in the offspring [53] and is a leading preventable cause of birth defects and developmental disabilities [54-56]. Nonetheless, it is important to highlight the history of PAE in those studies. The estimated number of drinks consumed on a typical day during pregnancy was 0.47 (0.71) for the FASD group and 0.30 (0.49) for the control group in the study of Aragon et al. [43]. The women in the two alcohol consuming groups (FAS/PFAS and HE) in the study of Diwadkar et al. [44] concentrated their drinking on 1.2 to 1.4 days/week on average and women in both groups met criteria for the revised $\mathrm{Na}$ tional Institute on Alcohol Abuse and Alcoholism (United States) criterion for binge drinking by women (four or more drinks/occasion). In the study of Quattlebaum and O'Connor [47], a comprehensive history of PAE was obtained by means of the health interview for women. Among adopted or foster children, medical and legal record documentation, as well as reliable witness reports of PAE, were obtained. Children with unknown exposure were not included in the study. Researchers took rigorously steps to obtain reliable data about PAE. The fact that exposed participants meet diagnostic criteria for FASD according to dysmorphological examination suggest that the informed PAE might be underestimated.

The FASD has been used to emphasize the continuum nature of these effects [57] and the evidence from multiple studies demonstrate why alcohol remains the most widely studied prenatal drug of abuse [4]. One important contribution of studies analyzed here is that alcohol not only negatively affects physical characteristics (e.g., facial morphology, body size), but it also affects the development of specific neurocognitive processes such as WM [57]. Indeed, there is evidence that PDE in general may be a risk factor for specific deficits, rather than global deficit [58]. Hence, it may be useful to examine particular aspects of neurocognitive functioning which might be more sensitive to PDE than global assessments.

\section{Tobacco and WM}

Bennett et al. [48] did not find significant differences in WM between children prenatally exposed to tobacco and controls, but the result could be related to the small sample size $(n=18)$ and measure used (n-back task). Researchers have criticized the use of the $\mathrm{n}$-back task as a WM measure (see discussion below). In spite of this limitation, fMRI data revealed differences in brain activity during WM task between comparison groups [48], suggesting that WM examination in children prenatally exposed to tobacco using exclusively a neuropsychological assessment might be insufficient to detect differences between groups. A better approach is to combine neuropsychological assessment with neuroimaging techniques whenever possible.

\section{Cocaine and WM}

Hurt et al. [49] and Singer et al. [50] did not find significant effects of PCE on children's WM. Although the sample sizes of the studies were relatively large, they included several measures of PDE and also controlled confounding variables, the results were not generalizable because children were primarily African Americans. Findings of both studies showed that PCE is not a potent risk factor affecting children's cognitive development and stressed out the importance of identifying postnatal environmental factors to explain 
the performance [49]. In addition, their findings are consistent with a comprehensive review [6] that examined the effects of PCE on growth, cognitive ability, academic functioning and brain structure and function among school-aged children. After controlling for environmental factors, only PCE effects were reliably reported in sustained attention and behavioral self-regulation [6].

\section{Concerns regarding PDE research}

Relevant issues related to study designs, control of confounding variables and measures used in PDE research in general and WM research in particular are briefly discussed next.

\section{1) Study designs}

Limitations regarding the inclusion and exclusion criteria represent one issue. For instance, studies often exclude participants with physical, psychiatric, or developmental disabilities and therefore, findings might not be sustained in samples with these particular conditions. Another concern are the sample sizes because some studies have used small samples for justified reasons (e.g., budget, technical support) although larger samples have more power to detect differences between groups.

\section{2) Control of confounding variables}

Controversial findings in PDE research might relate to inadequate attention of potential confounders. For instance, the mothers of children prenatally exposed to drugs are frequently poly-substance users and consequently, multiple drug interactions might underlie the deficits observed. Researchers should analyze the results with discretion, avoiding the attribution of effects exclusively to one drug, as samples with single drug exposures are difficult to find and would not be relevant to the populations under study [59]. In addition to differences in PDE (e.g., type of drug, frequency) postnatal factors such as SES, caregiver psychopathology and violence experiences might influence the results. Factors contributing to childhood disability include caretakers' characteristics and behaviors, inadequate housing, crowding, deviant peer and adult models, poorly educated adult models, inadequate health care access and minority status [3]. Hence, it becomes necessary to consider sociodemographic, medical and environmental factors in PDE research.

\section{3) Measures}

Another important issue in PDE research relates to reliable drug exposure measures [60]. The prevailing methods to detect PDE are maternal self-reports and urine toxicology screens. Although self-reports are cost-effective methods to assess time and amount of drug use during pregnancy, the veracity and recall accuracy could be questioned in studies relying exclusively on self- reports [4]. Given that precise information of drug exposure is difficult to recall and might be affected by the stigma of admitting drug use during pregnancy, drug use during this period is often non-disclosed. On the other hand, urine toxicology screens allow the detection of several drugs, but they only detect recent use, provide no information about frequency and quantity, and could underreport exposure given drugs' detection span [61-63]. Konijnenberg [60] proposes the use of maternal self-reports and laboratory tests in PDE studies.

Using particular assessment instruments might be also problematic if they are not suitable for examining the outcome of interest. For example, it could be the use of instruments translated to the language of the population to be studied without psychometric properties for that population. An Afrikaans translation of the WISC-IV was used in the study of Diwadkar et al. [44]. Moreover, the use of measurement instruments for which the psychometric properties have not been examined or the empirical evidence does not support their use, represents an ethical issue. Results and interpretations from instruments without adequate psychometric properties must be taken with discretion.

\section{4) Measures of WM}

WM research has been complicated by the various definitions of WM itself and theoretical framework assumed, yielding different methods of assessment [64]. Researchers must use measures with sufficient sensitivity to detect WM deficits in children. Such process implies analyzing each task to ensure that cognitive (e.g., sustain attention, speed processing) and non-cognitive (e.g., computer or communication skills) demands are similar among them.

Another problem relates to how task performance is measured. From a research perspective, computerized cognitive tasks comprise standardized administration and data gathering from a large numbers of trials, including reaction time measures [65], but participants' computer abilities could affect the results [64]. Computerized tasks might also be less sensitive than manual tasks for measuring executive function deficits in specific clinical groups and they might have poor ecological validity [65].

The distinction between simple and complex span tasks reflects the difficult context regarding the assessment of WM. Simple span tasks require to immediately recall short lists of stimulus while complex span tasks involve both storage and control processes that maintain the information accessible in the service of higher-order cognition [66]. When translating this into PDE research, perhaps simple tasks might not discriminate between children prenatally exposed to drugs and non-exposed children. It seems that complex tasks might be most sensitive to behavioral performance differenc- 
es among children prenatally exposed to drugs [43].

The classification of a WM measure as either simple or complex should be derived not only from theoretical analyses, but also from empirical data. Two frequently used measures to assess WM, the Digit Span subtest from the WISC and the n-back tasks, could illustrate this issue. The Digit Span subtest is a recall measure of numerical sequences of increasing difficulty. It comprises a forward condition (simple task) and a backward condition (complex task). Even though it can be regarded as a WM measure, the performance may be influenced by other factors such as attention and comprehension [43]. N-back tasks are continuous-recognition measures that present sequences of stimulus and the participant decides whether it matches the one appeared $\mathrm{n}$ items ago. $\mathrm{N}$-back has face validity as a WM task because participants must rehearse and update sequence while responding to each item. However, in contrast to WM spans, empirical validation of the n-back task as a WM measure are limited [67]. In one of the few published studies [66], researchers found that the n-back and WM span were weakly correlated, suggesting that they do not reflect a single construct. Authors stated that the results of their study provide little evidence of n-back's validity as a WM task measuring the same executive processes involved in complex span. Retrieval demands between the complex span and the n-back are different because the first one demands serial recall, while the latter demands recognition. Recall tasks more realistically reflects the complex cognitive behavior exhibited in reading, reasoning and problem solving because all require the rapid recall of recently acquired knowledge [68]. In addition, despite its widespread use in neuroimaging studies, investigation of the n-back as a clinical measure is scarce [69]. Its clinical utility to predict cognitive ability is not clear, but the n-back task is useful in WM research because it allows load to be manipulated in a simple way [67].

Research that incorporates more than one type of data would enhance the results. For example, fMRI is a non-invasively method to assess brain activity during cognitive, perceptual or motor tasks $[48,70]$ and it has been used in PDE studies to detect differences in brain activity even when neuropsychological or behavioral outcomes appear unaffected. Brain imaging might reveal differences in neural activity during task performance and thus, it is recommended to focus on qualitative and quantitative data at both the behavioral and neural level.

\section{Conclusion}

The limited number of studies discussed in this systematic review did not allow us to establish conclusions about the effects of PDE on children's WM. However, it is clear that alcohol exposure in utero continues to be a major public health concern. Based on the studies reviewed here, PAE seems to negatively affect children's WM. In addition, one relevant methodological constrain we found relates to the variety of instruments and tools (e.g., psychological testing, computerized tasks) used to measure WM. Multiple ways of measuring WM might affect the results and consequently, the conclusions reached. Although inconsistencies in the results of studies exploring PDE and WM may be associated with these and perhaps other methodological issues, they represent together a major challenge for neurology, neuropsychology and cognitive sciences in general. Well-designed studies to obtain more precise information about the effects of PDE in children's WM are strongly recommended.

\section{Limitations}

The present systematic review has several limitations that should be addressed. First, our study was limited to electronic publication search, occluding publications in printed journals that perhaps complied with the inclusion criteria. However, we supplemented the electronic search with a revision of references cited in the articles to identify other relevant studies and compensate partially for this limitation. A second constraint was the participants' age range ( 5 to 12 years old). As mentioned before, this systematic review focused on this particular age range because school endeavors demand complex cognitive competences during this life period. Such demands could evidence the effects of PDE that would be difficult to identify and intervene at an early age or in other settings. A third limitation is the year of publication (2008 to 2019). We selected those specific years to include recent findings on this topic and therefore, previous studies were excluded. In spite of these limitations, this systematic review provides relevant implications for future research exploring specific causal relationships between PDE and WM.

\section{Conflicts of interest}

No potential conflict of interest relevant to this article was reported.

\section{ORCID}

Samariz Laboy-Hernández, http://orcid.org/0000-0002-08746291

Nelson D. Cruz-Bermúdez, http://orcid.org/0000-0003-06581005

\section{Author contribution}

Formal analysis: SLH and NDCB. Funding acquisition: NDCB. 
Methodology: NDCB, and GB. Project administration: SLH and NDCB. Visualization: SLH and NDCB. Writing-original draft: SLH. Writing-review \& editing: SLH, NDCB, and GB.

\section{Acknowledgements}

Research reported in this publication was supported by the National Institute on Minority Health and Health Disparities and the National Institute of Allergy and Infectious Diseases of the National Institutes of Health under award number U54MD007587 and by the Institutional Fund for Research, University of Puerto Rico, Río Piedras Campus (to Nelson D. Cruz-Bermúdez).

\section{References}

1. Forray A. Substance use during pregnancy. F1000Res 2016;5:F1000 Faculty Rev-887.

2. Thompson BL, Levitt P, Stanwood GD. Prenatal exposure to drugs: effects on brain development and implications for policy and education. Nat Rev Neurosci 2009; 10:303-12.

3. Martin RP, Dombrowski SC. Prenatal exposures: psychological and educational consequences for children. New York: Springer; 2008.

4. Behnke M, Smith VC; Committee on Substance Abuse; Committee on Fetus and Newborn. Prenatal substance abuse: short- and long-term effects on the exposed fetus. Pediatrics 2013;131:e100924.

5. Irner TB. Substance exposure in utero and developmental consequences in adolescence: a systematic review. Child Neuropsychol 2012;18:521-49.

6. Ackerman JP, Riggins T, Black MM. A review of the effects of prenatal cocaine exposure among school-aged children. Pediatrics 2010;125:554-65.

7. Bay B, Kesmodel US. Prenatal alcohol exposure: a systematic review of the effects on child motor function. Acta Obstet Gynecol Scand 2011;90:210-26.

8. Kwiatkowski MA, Roos A, Stein DJ, Thomas KG, Donald K. Effects of prenatal methamphetamine exposure: a review of cognitive and neuroimaging studies. Metab Brain Dis 2014;29:245-54.

9. Banderali G, Martelli A, Landi M, Moretti F, Betti F, Radaelli G, et al. Short and long term health effects of parental tobacco smoking during pregnancy and lactation: a descriptive review. J Transl Med 2015;13:327.

10. Substance Abuse and Mental Health Services Administration. Results from the 2013 National Survey on Drug Use and Health: Summary of National Findings [Internet]. Rockville:
SAMHSA; 2014 [cited 2020 Jun 30]. Available from: https:// store.samhsa.gov/product/Results-from-the-2013-NationalSurvey-on-Drug-Use-and-Health-Summary-of-National-Findings/sma14-4863.

11. European Monitoring Center for Drugs and Drug Addiction. The state of the drugs problems in Europe: annual report 2012. Luxembourg: Publications Office of the European Union; 2012.

12. Anthony EK, Austin MJ, Cormier DR. Early detection of prenatal substance exposure and the role of child welfare. Child Youth Serv Rev 2010;32:6-12.

13. Wendell AD. Overview and epidemiology of substance abuse in pregnancy. Clin Obstet Gynecol 2013;56:91-6.

14. Stephen G, Whitworth MK, Cox S. Substance misuse in pregnancy. Obstet Gynaecol Reprod Med 2014;24:309-14.

15. Bennett DS, Bendersky M, Lewis M. Children's cognitive ability from 4 to 9 years old as a function of prenatal cocaine exposure, environmental risk, and maternal verbal intelligence. Dev Psychol 2008;44:919-28.

16. Clifford A, Lang L, Chen R. Effects of maternal cigarette smoking during pregnancy on cognitive parameters of children and young adults: a literature review. Neurotoxicol Teratol 2012;34:560-70.

17. Diaz SD, Smith LM, LaGasse LL, Derauf C, Newman E, Shah R, et al. Effects of prenatal methamphetamine exposure on behavioral and cognitive findings at 7.5 years of sge. J Pediatr 2014;164:1333-8.

18. Flak AL, Su S, Bertrand J, Denny CH, Kesmodel US, Cogswell ME. The association of mild, moderate, and binge prenatal alcohol exposure and child neuropsychological outcomes: a meta-analysis. Alcohol Clin Exp Res 2014;38:214-26.

19. Kodituwakku PW, Segall JM, Beatty GK. Cognitive and behavioral effects of prenatal alcohol exposure. Future Med $2011 ; 6: 237-59$

20. Logie RH, Cowan N. Perspectives on working memory: introduction to the special issue. Mem Cognit 2015;43:315-24.

21. Kirkwood MW, Hargrave DD, KirkJW. The value of the WISCIV Digit Span subtest in detecting noncredible performance during pediatric neuropsychological examinations. Arch Clin Neuropsychol 2011;26:377-84.

22. Kirchner WK. Age differences in short-term retention of rapidly changing information. J Exp Psychol 1958;55:352-8.

23. Selvaggi Fadden K. Developmental assessment of the schoolage child. In: Carey WB, Crocker AC, Coleman WL, Elias ER, Feldman HM, editors. Developmental-behavioral pediatrics. 4th ed. Philadelphia: Saunders; 2009.p. 797-802.

24. Alloway TP, Alloway RG. Investigating the predictive roles of 
working memory and IQ in academic attainment. J Exp Child Psychol 2010;106:20-9.

25. Bull R, Espy KA, Wiebe SA. Short-term memory, working memory, and executive functioning in preschoolers: longitudinal predictors of mathematical achievement at age 7 years. Dev Neuropsychol 2008;33:205-28.

26. Sedek G, Krejtz I, Rydzewska K, Kaczan R, Rycielski P. Three functional aspects of working memory as strong predictors of early school achievements: the review and illustrative evidence. Pol Psychol Bull 2016;47:103-11.

27. Cornoldi C, Carretti B, Drusi S, Tencati C. Improving problem solving in primary school students: the effect of a training programme focusing on metacognition and working memory. $\mathrm{Br} \mathrm{J}$ Educ Psychol 2015;85:424-39.

28. Simmons FR, Willis C, Adams AM. Different components of working memory have different relationships with different mathematical skills.J Exp Child Psychol 2012;111:139-55.

29. Andersson U. The contribution of working memory capacity to foreign language comprehension in children. Memory 2010;18:458-72.

30. Gomez-Veiga I, Vila JO, Garcia-Madruga JA, Contreras A, Elosua MR. Comprension lectora y procesos ejecutivos de la memoria operativa. Psicol Educ 2013;19:103-11.

31. Gonzalez-Hernandez K, Otero-Paz L, Castro-Laguardia AM. Comprension lectora, memoria de trabajo, fluidez y vocabulario en escolares cubanos. Actual Investig Educ 2016;16:1-18.

32. Nevo E, Breznitz Z. Effects of working memory and reading acceleration training on improving working memory abilities and reading skills among third graders. Child Neuropsychol 2014;20:752-65.

33. Roberts G, Quach J, Gold L, Anderson P, Rickards F, Mensah F, et al. Can improving working memory prevent academic difficulties? A school based randomised controlled trial. BMC Pediatr 2011;11:57.

34. Rappley MD, Kallman JR. Middle childhood. In: Carey WB, Crocker AC, Coleman WL, Elias ER, Feldman HM, editors. Developmental-behavioral pediatrics. 4th ed. Philadelphia: Saunders; 2009. p. 50-61.

35. Best JR, Miller PH, Jones LL. Executive functions after age 5: changes and correlates. Dev Rev 2009;29:180-200.

36. Goldschmidt L, Richardson GA, Willford J, Day NL. Prenatal marijuana exposure and intelligence test performance at age 6. J Am Acad Child Adolesc Psychiatry 2008;47:254-63.

37. Klingberg T. Training and plasticity of working memory. Trends Cogn Sci 2010;14:317-24.

38. Rasmussen C, Treit S, Pei J. Memory interventions for children with memory deficits. In: Blouin M, Stone J, editors. Interna- tional encyclopedia of rehabilitation memory. New York: CIRRIE; 2010. p. 1-13.

39. The Joanna Briggs Institute. Joanna Briggs Institute Reviewers' Manual 2015. Adelaide: The Joanna Briggs Institute; 2015.

40. Abar B, LaGasse LL, Derauf C, Newman E, Shah R, Smith LM, et al. Examining the relationships between prenatal methamphetamine exposure, early adversity, and child neurobehavioral disinhibition. Psychol Addict Behav 2013;27:662-73.

41. Cohen MJ. Children's memory scale. In: Kreutzer JS, DeLuca J, Caplan B, editors. Encyclopedia of clinical neuropsychology. New York: Springer; 2011.p. 556-9.

42. Piper BJ, Acevedo SF, Kolchugina GK, Butler RW, Corbett SM, Honeycutt EB, et al. Abnormalities in parentally rated executive function in methamphetamine/polysubstance exposed children. Pharmacol Biochem Behav 2011;98:432-9.

43. Aragon AS, Coriale G, Fiorentino D, Kalberg WO, Buckley D, Gossage JP, et al. Neuropsychological characteristics of Italian children with fetal alcohol spectrum disorders. Alcohol Clin Exp Res 2008;32:1909-19.

44. Diwadkar VA, Meintjes EM, Goradia D, Dodge NC, Warton C, Molteno CD, et al. Differences in cortico-striatal-cerebellar activation during working memory in syndromal and nonsyndromal children with prenatal alcohol exposure. Hum Brain Mapp 2013;34:1931-45.

45. Schweitzer JB, Riggins T, Liang X, Gallen C, Kurup PK, Ross TJ, et al. Prenatal drug exposure to illicit drugs alters working memory-related brain activity and underlying network properties in adolescence. Neurotoxicol Teratol 2015;48:69-77.

46. Roussotte FF, Rudie JD, Smith L, O'Connor MJ, Bookheimer SY, Narr KL, et al. Frontostriatal connectivity in children during working memory and the effects of prenatal methamphetamine, alcohol, and polydrug exposure. Dev Neurosci 2012;34:43-57.

47. Quattlebaum JL, O'Connor MJ. Higher functioning children with prenatal alcohol exposure: is there a specific neurocognitive profile? Child Neuropsychol 2013;19:561-78.

48. Bennett DS, Mohamed FB, Carmody DP, Malik M, Faro SH, Lewis M. Prenatal tobacco exposure predicts differential brain function during working memory in early adolescence: a preliminary investigation. Brain Imaging Behav 2013;7:49-59.

49. Hurt H, Betancourt LM, Malmud EK, Shera DM, Giannetta JM, Brodsky NL, et al. Children with and without gestational cocaine exposure: a neurocognitive systems analysis. Neurotoxicol Teratol 2009;31:334-41.

50. Singer LT, Nelson S, Short E, Min MO, Lewis B, Russ S, et al. Prenatal cocaine exposure: drug and environmental effects at 9 years.J Pediatr 2008;153:105-11.

51. Minzenberg MJ. Pharmacotherapy for attention-deficit/hyper- 
activity disorder: from cells to circuits. Neurotherapeutics 2012;9:610-21.

52. Gau SS, Shang CY. Improvement of executive functions in boys with attention deficit hyperactivity disorder: an open-label follow-up study with once-daily atomoxetine. Int J Neuropsychopharmacol 2010;13:243-56.

53. Kodituwakku PW. Neurocognitive profile in children with fetal alcohol spectrum disorders. Dev Disabil Res Rev 2009;15:21824.

54. Coles CD. Discriminating the effects of prenatal alcohol exposure from other behavioral and learning disorders. Alcohol Res Health 2011;34:42-50.

55. Floyd RL, Jack BW, Cefalo R, Atrash H, Mahoney J, Herron A, et al. The clinical content of preconception care: alcohol, tobacco, and illicit drug exposures. Am J Obstet Gynecol 2008;199(6 Suppl 2):S333-9.

56. Fuentes Soliz JA, Vidal Lia OV, Fuentes Moya JM, Lopez E. Consumo de alcohol durante el embarazo: múltiples efectos negativos en el feto [Alcohol consumption during pregnancy: many adverse effects on the fetus]. Rev Cient Cienc Med 2009; 12:26-31.

57. Mattson SN, Crocker N, Nguyen TT. Fetal alcohol spectrum disorders: neuropsychological and behavioral features. Neuropsychol Rev 2011;21:81-101.

58. Nair P, Black MM, Ackerman JP, Schuler ME, Keane VA. Children's cognitive-behavioral functioning at age 6 and 7: prenatal drug exposure and caregiving environment. Ambul Pediatr 2008;8:154-62.

59. Roussotte FF, Bramen JE, Nunez SC, Quandt LC, Smith L, O'Connor MJ, et al. Abnormal brain activation during working memory in children with prenatal exposure to drugs of abuse: the effects of methamphetamine, alcohol, and polydrug exposure. Neuroimage 2011;54:3067-75.
60. Konijnenberg C. Methodological issues in assessing the impact of prenatal drug exposure. Subst Abuse 2015;9(Suppl 2):39-44.

61. Cotten SW. Drug testing in the neonate. Clin Lab Med 2012;32:44966.

62. Huizink AC. Prenatal substance use, prenatal stress and offspring behavioural outcomes: considerations for future studies. Nord J Psychiatry 2012;66:115-22.

63. Narkowicz S, Plotka J, Polkowska Z, Biziuk M, Namiesnik J. Prenatal exposure to substance of abuse: a worldwide problem. Environ Int 2013;54:141-63.

64. Best JR, Miller PH. A developmental perspective on executive function. Child Dev 2010;81:1641-60.

65. Hughes C. Changes and challenges in 20 years of research into the development of executive functions. Infant Child Dev 2011;20:251-71.

66. Kane MJ, Conway ARA, Miura TK, Colflesh GJH. Working memory, attention control, and the N-back task: a question of construct validity. J Exp Psychol Learn Mem Cogn 2007;33:61522.

67. Jaeggi SM, Buschkuehl M, Perrig WJ, Meier B. The concurrent validity of the $\mathrm{N}$-back task as a working memory measure. Memory 2010;18:394-412.

68. Chein JM, Moore AB, Conway AR. Domain-general mechanisms of complex working memory span. Neuroimage 2011;54:550-9.

69. Miller KM, Price CC, Okun MS, Montijo H, Bowers D. Is the n-back task a valid neuropsychological measure for assessing working memory? Arch Clin Neuropsychol 2009;24:711-7.

70. Astley SJ, Aylward EH, Olson HC, Kerns K, Brooks A, Coggins TE, et al. Functional magnetic resonance imaging outcomes from a comprehensive magnetic resonance study of children with fetal alcohol spectrum disorders. J Neurodev Disord 2009; 1:61-80. 